\title{
Composites of Styrene-Butadiene Block-Copolymer Reinforced with Waste Printed Circuit Boards (WPCB)
}

\author{
PAUL GHIOCA, RAMONA MARINA GRIGORESCU*, LORENA IANCU, \\ RODICA-MARIANA ION, MADALINA-ELENA DAVID, MIRCEA IOAN FILIPESCU, \\ ELENA RAMONA ANDREI, BOGDAN SPURCACIU, CRISTIAN-ANDI NICOLAE, \\ RALUCA GABOR
}

National Institute For Research \& Development In Chemistry \& Petrochemistry - ICECHIM, 202 Splaiul Independentei, 060021, Bucharest, Romania

\begin{abstract}
In recent years, the rapid development of electronic equipment led to millions of tons of waste printed circuit boards (WPCB) generated in the entire world rising important concerns regarding its recycling. Besides the metals recovery, intensively studied, the reuse of the nonmetals is especially difficult. In this study, the non-metallic fraction from the waste of printed circuit boards is used as reinforcing filler of a styrene-butadiene block-copolymer. The composites were characterized by mechanical and dynamo-mechanical analysis and thermo-gravimetry. The study aimed the reintroduction into the economic circuit of WPCB as composites suitable for the production of shoe soles injected directly on the footwear faces and as bitumen modifiers for road coverings.
\end{abstract}

Keywords: styrene-butadiene block-copolymer, non-metallic fraction of WPCB, paraffin-naphtenic oil extender, reinforcing effect

\section{Introduction}

The recycling of out of use printed circuits boards (WPCB) has been accentuated lately, in particular due to the fact that the recovery of the metallic component ensures economic profitability of the various physical and chemical processes. The non-metallic component resulting as a by-product of the extraction of metallic circuits is still to a small extent recycled, because consists in a thermosetting epoxy resin, glass fiber and flame retardants, a very difficult composition to reuse $[1,2]$, constituting a secondary pollution source due to storage and especially to landfill [3-5].

The increasingly stringent regulations imposed on the protection of the environment against pollution with WPCB have boosted worldwide the research regarding the introduction of the nonmetallic component of WPCB, with an important share of about 28-55\%, in the economic circuit [6].

Due to the thermo-rigidity of WPCB, the researches largely focused on the physical reuse of the non-metallic component as powder with a wide range of dimensions (nano-, micro- and millimeter), for bitumen additives, light concrete with antiphonal properties, obtaining reinforcing agents for polyolefins or as filler for adhesives and various building materials [4, 6-18].

The researches have led to the obtaining of a wide range of products with competitive properties compared to other materials in the respective fields, but their introduction in the economic circuit is slow.

The objective of the paper research is to diversify the recycling domain of the non-metallic fraction of WPCB used as a reinforcing material of styrene-butadiene block copolymers in order to obtain masterbatch composites for the production of shoe soles directly injected on the footwear faces, but also to modify bitumen for road coatings.

\footnotetext{
*email:rmgrigorescu@gmail.com
} 


\section{Materials and methods}

The reinforcing study was achieved using a star styrene-butadiene block-copolymer (SBS SOL T 161C supplied by Europrene) with a $32 \%$ polystyrene content and a molecular mass of 190.000 $\mathrm{g} / \mathrm{mole}$. This elastomer is usually used for composites for obtaining shoe soles directly injected on the footwear faces.

The non-metallic fraction of WPCB, resulting after the recovery of metals, milled to sub-millimeter dimensions, was used as a reinforcing agent to a maximum dosage of $30 \%$. In order to countervail the effect of increasing melt viscosity produced by the reinforcing filler of the non-metallic fraction and to fluidize the material in order to improve the thermal processing, a part of the composites were expanded by $25 \%$ paraffin-naphthenic oil ("white heavy oil"), whose characteristics are presented in table 1.

Table 1. Characteristics of the extender oil

\begin{tabular}{|c|c|c|}
\hline Nr. crt. & Property & Values \\
\hline 1. & Color & Colorless \\
\hline 2. & Density at $25^{\circ} \mathrm{C}, \mathrm{g} / \mathrm{cm}^{3}$ & 1,4740 \\
\hline 3. & Refraction index at $25^{\circ} \mathrm{C}$ & 418 \\
\hline 4. & Average molecular weight, $\mathrm{g} / \mathrm{mole}$ & 0,134 \\
\hline 5. & Kinematic viscosity at $38^{\circ} \mathrm{C}, \mathrm{m}^{2} / \mathrm{h}$ & 66,6 \\
\hline 6. & Structural composition, $\%$ & 29,9 \\
& C paraffinic & 3,5 \\
& C naphthenic & C aromatic \\
\hline
\end{tabular}

The paraffin-naphthenic oil is incompatible with the polystyrene phase, acting only as an extender of the continuous polybutadiene phase. Not affecting the polystyrene phase, which ensures the physical vulcanization of the elastomeric composition, is essential for maintaining the physicalmechanical properties of the material at high values [19-21].

The reinforcement study with the non-metallic fraction of WPCB was carried out in the tetrahydrofuran solution of the SBS block-copolymer of concentration $20 \%$. The dosage of the reinforcing filler was achieved in steps of 5\% to $30 \%$, the maximum limit being imposed by the maintenance of polybutadiene as the continuous phase of the extended or un-extended composite material with white-heavy oil [22, 23].

The desolventation was achieved by centrifugal casting at a temperature of $50-60{ }^{\circ} \mathrm{C}$, for $3-4 \mathrm{~h}$, obtaining films of about $1 \mathrm{~mm}$ thickness. The complete removal of the solvent was carried out in a vacuum oven at $60{ }^{\circ} \mathrm{C}$. The films thus conditioned served to determine the physico-mechanical and thermal properties of the composites.

The tensile properties were determined using a FPZ-100 dynamometer at a stretching speed of 500 $\mathrm{mm} / \mathrm{min}$, on specimens stamped from the tested films, according to SR EN ISO 527-96.

The dynamic mechanical analysis (DMA) was achieved using a Q800 V20.24 DMA instrument (TA Instruments), in air atmosphere, with $1 \mathrm{~Hz}$ frequency, at $-105 \div 155{ }^{\circ} \mathrm{C}$, and speed of $5{ }^{\circ} \mathrm{C} / \mathrm{min}$. Storage modulus ( $\left.\mathrm{E}^{\prime}\right)$, loss modulus ( $\left.\mathrm{E}^{\prime \prime}\right)$ and Tan $\delta$ temperature dependences were recorded.

Thermal stability was analyzed by thermogravimetric analysis (TGA) using a Q5000IR instrument (TA Instruments). Method: 1) Ramp $10^{\circ} \mathrm{C} / \mathrm{min}$ to $700^{\circ} \mathrm{C}$; 2) Select gas 2 ; 3) Isothermal for 5 minutes; purge gas 1: Nitrogen; purge gas 2: Air; sample pan: Platinium 100 $\mu \mathrm{L}$.

\section{Results and discussions}

The non-metallic fraction recovered after metals extraction consists, in particular, in a proportion of 99\% epoxy resin, glass fiber and silica fillers [6] which is distributed only in the continuous butadiene phase of the SBS block-copolymer due to the incompatibility with the polystyrene phase.

From the DMA analysis, a small and random variation of the glass transition of the polystyrene phase (Figure 1) can be observed in case of the un-extended SBS composites depending on the dosage 
of the non-metallic fraction of WPCB, whereas in the case of the extended composites with whiteheavy oil, the polystyrene Tg is practically not influenced by the filler dosage (Figure 2).
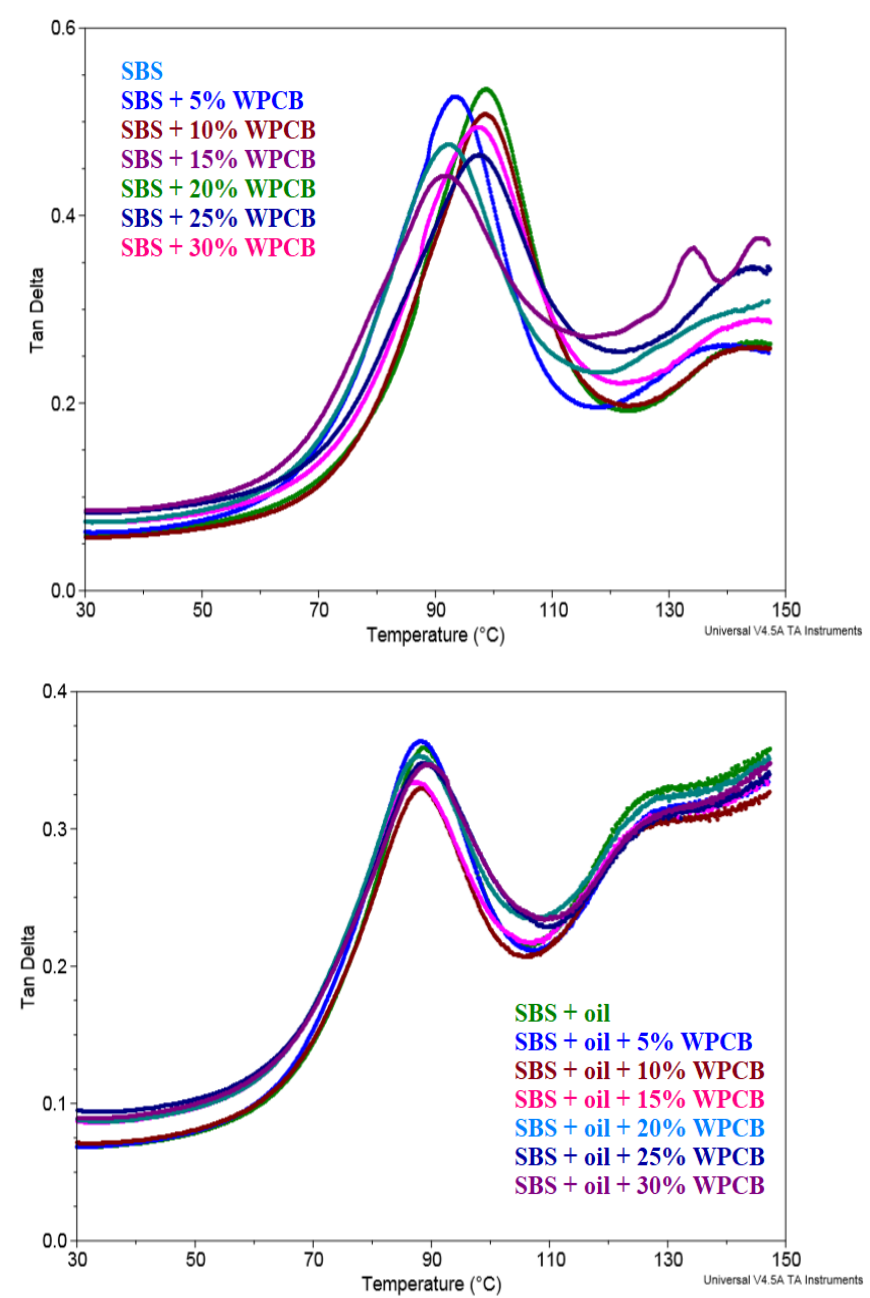

Figure 1. The variation of tan Delta for un-extended SBS-WPCB composites
Figure 2. The variation of tan Delta for oil extended SBS-WPCB composites

For the un-extended composites, the small increase and variation of the $\mathrm{Tg}$ recorded for the polystyrene phase is due to the presence of the non-metallic filler of the WPCB in the transition area of the polystyrene domains dispersed in the continuous polybutadiene phase. The presence of the whiteheavy oil into the polybutadiene phase of the extended composites allows the further separation of the polystyrene domains due to the strong incompatibility with the polystyrene domains and the decrease of the viscous behavior of the material. Also, by minimizing the transition zone, the polystyrene $\mathrm{Tg}$ is not significantly influenced due to the non-metallic filler of the WPCB. This filler does not produce the modification of the polystyrene network of the SBS block copolymer, which ensures the vulcanized elastomer character of the composites. The presence of the non-metallic filler of the WPCB in the continuous polybutadiene phase of the SBS block-copolymers produces a decrease of the tensile strength and elongation to break, highlighting the incompatibility between the two phases, mainly due to the polarity of the epoxy resin. The effect is similar in the case of the non-extended and extended material, as can be seen from Figures 3 and 4.

It must be observed that the glass fiber from WPCB has a reinforcing effect evidenced by both the increase of the storage module (Figures 5 and 6) and loss module (Figures 7 and 8) attenuated by the relatively large sub millimeter dimensions of the filler [24, 25].

According to literature, SBS composites are used in the production of shoe soles due to the easy processing by direct injection on the footwear faces, a process that increases the productivity and reduces the labor costs by eliminating the vulcanization phase required in the use of general-use rubbers (SBR, PB, PI and natural rubber). 

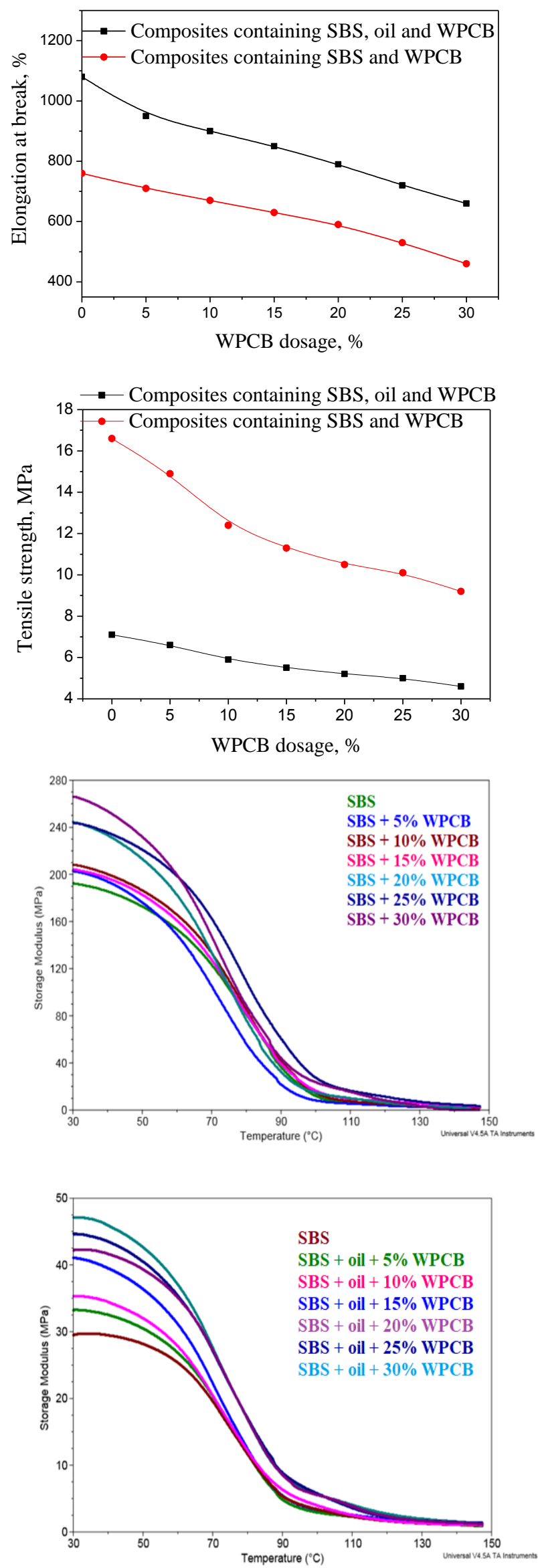

Figure 3. The tensile strength of SBS-WPCB composites

Figure 4. The elongation at break of SBS-WPCB composites

Figure 5. The variation of the storage modulus for un-extended SBS-WPCB composites

Figure 6. The variation of the storage modulus for oil extended SBS-WPCB composites 

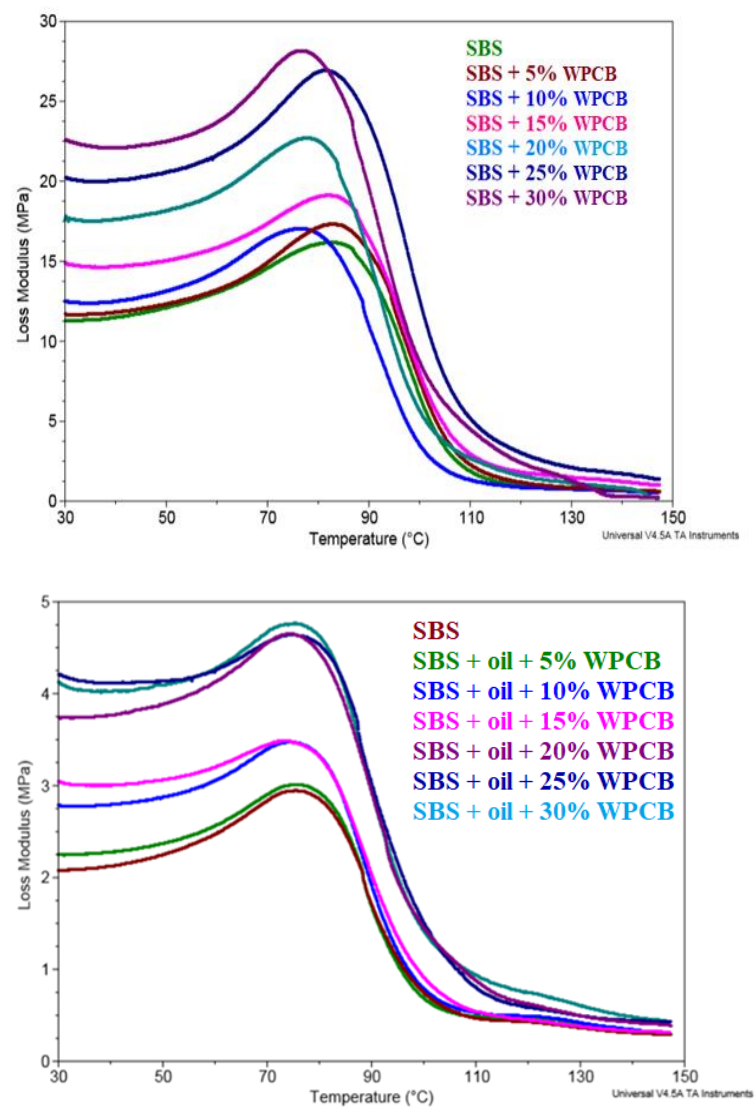

Figure 7. The variation of the loss modulus for un-extended SBSWPCB composites

Figure 8. The variation of the loss modulus for oil extended SBSWPCB composites

For commonly manufactured footwear soles, the physical-mechanical indicators mentioned in the literature $[26,27]$ have the following values:

- Tensile strength: 5-10 MPa;

- Elongation at break: $500-700 \%$ (up to $1000 \%$ for sports shoes);

- Hardness: 50- 80 ShA.

As can be seen in Figures 1 and 2, these technical requirements are met even at the maximum dosage of WPCB filling for the $25 \%$ extended paraffin-naphthenic oil composites, which recommends the use of these materials as masterbatch for the production of shoe soles by direct injection on the footwear. A special application of these composites is the sport footwear due to the good adhesion of the SBS composites to the pavement, to wet asphalt and to the synthetic surfaces of the sports fields.

The thermal stability of the non-metallic part of the WPCB and of the non-extended and extended composites with paraffin-naphthenic oil was analyzed by thermogravimetry (TGA) and in figures 9 and 10 the thermograms of the two series of compounds are presented.

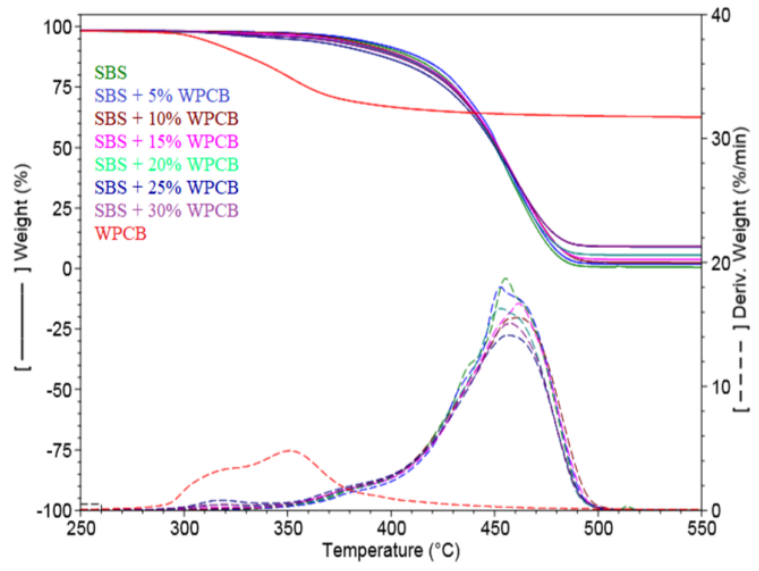

Mater. Plast., 57 (1), 2020, 92-99
Figure 9. Thermal stability of un-extended SBSWPCB composites 


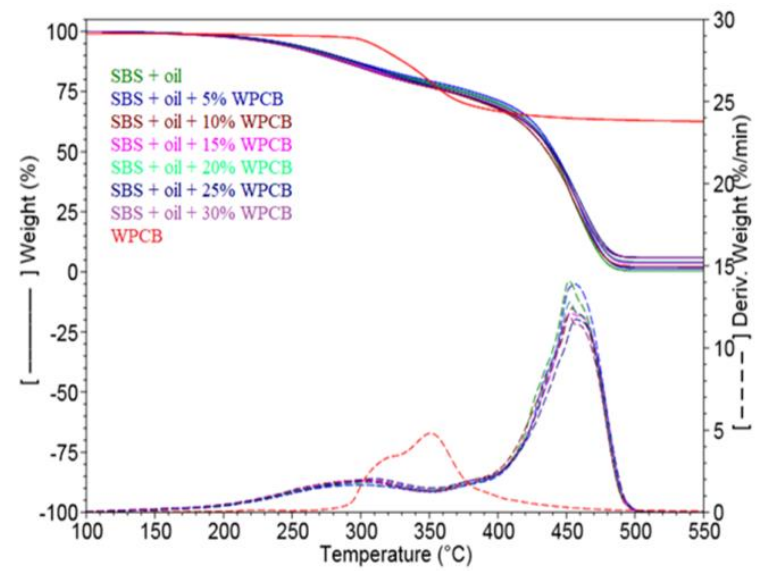

Figure 10. Thermal stability of extended SBS-WPCB composites

From thermograms and tables 2 and 3 it can be seen that the non-metallic part of the WPCB has a good thermal stability up to $260{ }^{\circ} \mathrm{C}$, followed by a decomposition of the total fraction of the polymeric part in the temperature range of $260-450{ }^{\circ} \mathrm{C}$, the final residue being $54.72 \%$ in air. Thus, it can be reported that the non-metallic part of WPCB contains $45.28 \%$ mostly epoxy resin and $54.72 \%$ glass fiber and silica fillers. Also, it can be appreciate that the reinforcing effect is due to the glass fiber and silica filling.

The presence of WPCB filling in the SBS block-copolymer composites slightly modifies their behavior to thermal degradation, the weight loss related to the same temperature ranges having a small and random variation (tables 2 and 3). The polybutadiene phase in which the nonmetallic part of the WPCB is included protects it against thermal degradation until the breakdown of this matrix and the exothermic growth from $450{ }^{\circ} \mathrm{C}$ (figs. 9 and 10) is due to the contribution of oxidation (combustion) of this organic filler.

Table 2. Thermal degradation steps of un-extended sbs-wpcb composites

\begin{tabular}{|c|c|c|c|c|c|c|c|c|c|c|}
\hline & \multicolumn{2}{|c|}{$\mathrm{RT}-260^{\circ} \mathrm{C}$} & \multicolumn{2}{|c|}{$260-335^{\circ} \mathrm{C}$} & \multicolumn{2}{|c|}{$335-395^{\circ} \mathrm{C}$} & \multicolumn{2}{|c|}{$395-700^{\circ} \mathrm{C}$} & \multicolumn{2}{|c|}{ Residue $700^{\circ} \mathrm{C}$} \\
\hline & Wt. loss & $\operatorname{Tmax}_{1}$ & Wt. loss & $\operatorname{Tmax}_{2}$ & Wt. loss & $\operatorname{Tmax}_{3}$ & Wt. loss & $\operatorname{Tmax}_{4}$ & $\left(\mathrm{~N}_{2}\right)$ & (Air) \\
\hline & $\%$ & ${ }^{\circ} \mathrm{C}$ & $\%$ & ${ }^{\circ} \mathrm{C}$ & $\%$ & ${ }^{\circ} \mathrm{C}$ & $\%$ & ${ }^{\circ} \mathrm{C}$ & $\%$ & $\%$ \\
\hline SBS & 1.89 & 142.3 & 0.44 & & 5.88 & 380.0 & 91.53 & 455.3 & 0.26 & 0.25 \\
\hline SBS-5\% WPCB & 1.72 & 171.8 & 0.57 & 315.2 & 5.17 & 379.0 & 90.78 & 453.1 & 1.76 & 1.73 \\
\hline SBS-10\% WPCB & 1.72 & 170.0 & 0.69 & 309.6 & 6.75 & 378.4 & 88.91 & 461.9 & 1.93 & 1.76 \\
\hline SBS-15\% WPCB & 1.79 & 461.5 & 1.10 & 377.6 & 6.78 & 0.0 & 86.72 & 318.2 & 3.61 & 3.27 \\
\hline SBS-20\% WPCB & 1.92 & 165.4 & 1.62 & 318.1 & 6.42 & 375.0 & 84.56 & 452.5 & 5.48 & 5.45 \\
\hline SBS-25\% WPCB & 1.56 & 138.7 & 2.68 & 317.7 & 7.92 & 374.9 & 79.01 & 456.7 & 8.83 & 8.31 \\
\hline SBS-30\% WPCB & 1.65 & 162.9 & 1.85 & 319.2 & 6.97 & 375.1 & 80.48 & 457.6 & 9.05 & 9.00 \\
\hline WPCB & 1.88 & 227.1 & 12.11 & 316.6 & 18.70 & 351.0 & 5.75 & & 61.57 & 54.72 \\
\hline
\end{tabular}


Table 3. Thermal degradation steps of oil extended sbs-wpcb composites

\begin{tabular}{|c|c|c|c|c|c|c|c|c|}
\hline & \multicolumn{2}{|c|}{$\mathrm{RT}-350^{\circ} \mathrm{C}$} & \multicolumn{2}{|c|}{$350-395^{\circ} \mathrm{C}$} & \multicolumn{2}{|c|}{$395-700^{\circ} \mathrm{C}$} & \multicolumn{2}{|c|}{ Residue $700^{\circ} \mathrm{C}$} \\
\hline & Wt. loss & $\operatorname{Tmax}_{1}$ & Wt. loss & $\operatorname{Tmax}_{2}$ & Wt. loss & $\operatorname{Tmax}_{3}$ & $\left(\mathrm{~N}_{2}\right)$ & (Air) \\
\hline & $\%$ & ${ }^{\circ} \mathrm{C}$ & $\%$ & ${ }^{\circ} \mathrm{C}$ & $\%$ & ${ }^{\circ} \mathrm{C}$ & $\%$ & $\%$ \\
\hline SBS & 21.41 & 295.4 & 7.32 & 374.4 & 70.94 & 452.0 & 0.33 & 0.33 \\
\hline SBS-5\% WPCB & 20.60 & 297.7 & 7.04 & 378.9 & 71.07 & 456.5 & 1.29 & 1.13 \\
\hline SBS-10\% WPCB & 23.21 & 301.2 & 7.85 & 376.9 & 66.86 & 453.9 & 2.08 & 2.04 \\
\hline SBS-15\% WPCB & 22.86 & 305.3 & 7.26 & 376.1 & 66.68 & 453.5 & 3.20 & 3.15 \\
\hline SBS-20\% WPCB & 21.89 & 307.7 & 7.26 & 380.5 & 66.94 & 452.8 & 3.91 & 3.90 \\
\hline SBS-25\% WPCB & 22.51 & 309.9 & 8.00 & 378.2 & 63.68 & 456.8 & 5.81 & 5.69 \\
\hline
\end{tabular}

There was no significant difference of the thermo-oxidative stability between the non-extended and extended SBS block-copolymer composites with paraffin-naphthenic oil, as can be seen from the thermograms shown in Figures 9 and 10.

It can be considered that the good stability to the thermal degradation of the SBS composites reinforced with the non-metallic part of the WPCB ensures a high durability of the footwear soles injected from these mixtures.

\section{Conclusions}

The compounding study of the SBS block-copolymers with the non-metallic part of WPCB revealed its incompatibility with the polystyrene domains and its distribution in the continuous polybutadiene phase, acting as reinforcing filler.

The extension with $25 \%$ paraffin-naphthenic oil, which dilutes only the polybutadiene phase, was necessary to improve the thermal processing of the composites as a result of reducing the viscosity in their melt state. The high physical-mechanical properties of the composites are due to the fact that the polystyrene domains of block-copolymer SBS were not affected thus ensuring to the mixtures the degree of physical cross-linking necessary to have a vulcanized elastomer character.

These composites, containing a maximum of $30 \%$ non-metallic fraction of WPCB, can be used as masterbatch for the production of a material suitable for obtaining shoe soles directly injected on the footwear.

The good thermal stability of these composites ensures a durable performance of the footwear made with soles injected from these blends.

Another important use of these composites is the additives of the bitumen used in road coatings, giving them the stability at deformation at high temperatures and preventing the formation of cracks at negative temperatures.

Acknowledgments: This paper was supported by a grant of the Romanian Ministery of Research and Innovation, CCCDI -UEFISCDI, project number PN-III-P1-1.2-PCCDI-2017-0652 / 84 PCCDI/2018, within PNCDI III, PN 19.23.02.01.04.

\section{References}

1. SOHAILI, J., MUNINANDI, S., K., SUHAILI, S., A., Materials, IJSER, 2012, p3 
2. SAHAJWALLA, V., CAYUMIL, R., KHAUNA, R., IKRAM-NI-HAQ, M., RAJARAO, R., MUKHERJEE, P., S., HILL, A., J. Sustain. Metall, 2015, 1, p75

3. MARQUES, A., C., CABRERA-MARRERO, J., M., de FRAGA-MALFATTI, C., Spinglerplus, 2, 2013, p521

4. ZENG, Y., Materials and Design 30, 2009, p958

5. MILLS, W., TATARA, R., A., Challenge 2016, 7, 13

6. HADI, P., XU, M., LIN, CSK, HUI, C.-W., McKAY, G., Journal of Hazardous Materials, 2014

7. GUO, JIU, GHO, Jie, XU, Z., Journal of Hazardous Materials, 168, 2009, p567

8. KUMAR, A., CHOUDHARY, V., KHANNA, R., TRIPATHI, S., N., IKRAM-NI-HAQ, M., SAHAJWALLA, V., J. Appl. Polym. Sci., 2016, p.1

9. LI, J., LU, H., GUO, J., XU, Z., ZHOU, Y., Envirom. Sci. Technol., 41, 2007, p.1995

10. PANYAKAPO, P., PANYAKAPO, M., Waste Manage, 28, 2008, p.1581

11. GUO, B., CAO, J., GUO, Z., XU, A., Envirom. Sci. Techn., 42 (14), 2008, p.5267

12. GUO, J., RAO, Q., XU, Z., J. Hazard. Mater., 153, 2008, p.728

13. LIANG, J., Z., J. Appl. Polym. Sci. 83, 2002, p.1547

14. MANTAUX, O., LORRIOT, T., CHIBALON, I., AURREKOETXEA, Y., PUERTO, A., AROSTECI, A., URRUTIBEASCOA, I., J., Mater. Sci. Tecnol. 20, 2004, p.125

15. BUEKENS, A., YANG, J., Y., Mater. Cycles Waste Manag. 16, 2014, p.415

16. PERRIN, D., MANTAUX, O., IENNY, P., LEGGER, R., DUMON, M., LOPEZ-CUESTA, J.-M., Waste Manag. 56, 2016, p.438

17. MOHD, HASAN, M., R., COLBERT, B., YOU, Z., JAMSHIDI, A., HEIDEN, P., A., HAMZAH, M., O., Constr. Built. Mater. 110, 2016, p79

18. CONG, P., CHEN, S., YU, J., CHEN, H., Int. J. Pavement Res. Technol. 4(2), 2011, p.118

19. HOLDEN, G., KRICHELDORF, H., R., QUIRK, R., P., Thermoplastic Elastomers, Hamser Publishers, 2004

20. HOLDEN, G., In Applied Plastics Engineering Handbook: processing and materials, KURTZ, M.,(Ed) WILLIAM ANDREW INC: Norwich, NY, USA, 2011

21. UTRACKI, L., A., WILKIE, C., Polymer Blends Handbook: Springer, Netherlands, 2014

22. SATAPATHY, B., K., LACH, R., WEIDI, SCH, R., SCHNEIDER, K., JANKE, A., KNOLL, Eng. Fract. Mec., 73, 2006, p. 2399

23. GRIGORESCU, R., M., GHIOCA, P., IANCU, L., GRIGORE, M., E., ANDREI, R., E., ION, R., M., NICOLAE, C., A., GABOR, R., Mate Plast., 56, (3), 2019, 510

24. CHO, J., JOSHI, M., S., SUN, C., T., Composites Science and Technology 66, 2006, p.1941

25. CHEN, J.-K., WANG, G., T., YU, Z., Z., HUANG, Z., MAI, Y., W., Composites Science and Technology 70, 2010, p.861

26. JOLENE, F., S., NUNES, RCE, Rheological Behavior of Mineral Fillers in Shoe Composites, Universidad de Rio de Janeiro, P.O Box 68525, Rio de Janeiro, RJ, Brazil, 2000

27. BUlBul, S., AKAKAlE, N., GOKMESE, H., GOK, O., YASAR, M., Int. Adv. Res. Eng. J., 1, 2017, p. 1

$\overline{\text { Manuscript received: } 16.12 .2019}$ 